\title{
Modification of the lithospheric stress field by lateral variations in plate-mantle coupling
}

\author{
J. B. Naliboff, ${ }^{1}$ C. P. Conrad, ${ }^{2}$ and C. Lithgow-Bertelloni ${ }^{3}$ \\ Received 10 August 2009; revised 2 October 2009; accepted 12 October 2009; published 25 November 2009.
}

[1] The presence of deeply penetrating continental roots may locally increase the magnitude of basal shear tractions by up to a factor of 4 compared to a layered viscosity structure. Here we examine how these increases in mantlelithosphere coupling influence stress patterns in the overlying elastic lithosphere. By coupling a mantle flow model to a model for the elastic lithosphere, we show that the amplification of mantle tractions beneath cratons increases elastic stress magnitudes by at most a factor of only 1.5 in a pattern not correlated to local basal traction changes. This disconnect is explained by the transmission of elastic stresses across large distances, which makes them sensitive to regionally-averaged changes in basal tractions, but not local variations. Our results highlight the importance of regional variations in lithospheric strength, which could allow stress patterns to more closely match regional changes in basal shear. Citation: Naliboff, J. B., C. P. Conrad, and C. Lithgow-Bertelloni (2009), Modification of the lithospheric stress field by lateral variations in plate-mantle coupling, Geophys. Res. Lett., 36, L22307, doi:10.1029/ 2009GL040484.

\section{Introduction}

[2] The relationship between mantle flow and the lithospheric stress field depends strongly on the rheological structure of the convecting mantle, asthenosphere and overlying lithosphere. Previous work has demonstrated that the presence of a laterally-varying viscosity structure in mantle flow models significantly enhances mantlelithosphere coupling beneath deeply penetrating continental roots [Zhong, 2001; Conrad and Lithgow-Bertelloni, 2006; Becker, 2006] as thicker lithosphere comes into closer contact with deeper and more viscous mantle. In the case of flow driven by mantle density variations, the magnitude of shear tractions at the base of deep continental roots increase by a factor of $2-5$ when laterally-varying and layered viscosity structures are compared [Conrad and Lithgow-Bertelloni, 2006]. Here, we look at how increases in shear tractions acting at the base of plates affect the stress field in the elastic lithosphere for a range of continental structures and different combinations of mantle flow

\footnotetext{
${ }^{1}$ Department of Geological Sciences, University of Michigan, Ann Arbor, Michigan, USA.

${ }^{2}$ Department of Geology and Geophysics, SOEST, University of Hawaii, Honolulu, Hawaii, USA.

${ }^{3}$ Department of Earth Sciences, University College London, London, United Kingdom.
}

Copyright 2009 by the American Geophysical Union. 0094-8276/09/2009GL040484 fields driven by mantle density heterogeneity and plate motions.

\section{Combined Modeling of Viscous Flow and Elastic Deformation}

[3] Because it is not yet possible to compute both mantle flow and lithospheric deformation within a single calculation at the global scale, we first calculate viscous shear stresses acting on the base of the lithosphere using a global flow model [Conrad and Lithgow-Bertelloni, 2006; Conrad et al., 2007] and then separately calculate the lithospheric response to these basal tractions [Bai et al., 1992; Bird, 1998; Steinberger et al., 2001; Lithgow-Bertelloni and Guynn, 2004; Ghosh et al., 2008] using a model for the elastic lithosphere [Lithgow-Bertelloni and Guynn, 2004]. First, we compute the viscous flow field driven by density variations or surface plate motions for a given viscosity structure and extract the horizontal and radial tractions that these flows exert on the base of the lithosphere. These tractions are in turn applied to the base of an elastic lithospheric model. This lithospheric model assumes a vertically and horizontally homogenous lithosphere in order is to isolate the relative effects of lateral variations in the depth of the lithosphere-asthenosphere boundary on lithospheric stresses.

\subsection{Viscous Flow}

[4] We compute global viscous flow using the finite element code CitcomS [Zhong et al., 2000; Tan et al., 2006] with details as described by Conrad et al. [2007]. To resolve basal tractions, we use horizontal and vertical resolutions of 105 and $17 \mathrm{~km}$, respectively, in the lithospheric and asthenospheric layers, and $100 \mathrm{~km}$ vertical resolution in the lower mantle. Flow is driven by internal density heterogeneity below $325 \mathrm{~km}$ (density-driven) determined from seismic tomography [Ritsema et al., 2004] $\left(0.15 \mathrm{~g} \mathrm{~cm}^{-3} \mathrm{~km}^{-1} \mathrm{~s}\right.$ [Karato and Karki, 2001] velocity to density conversion) or NUVEL-1A surface plate motions (plate-driven) [DeMets et al., 1994]. As in numerous previous studies the upper $325 \mathrm{~km}$ of the seismic model are excluded because they are partially affected by lithospheric compositional variations. For a Newtonian rheology we may add the density- and plate-driven flow fields to give the net tractions acting at the base of the lithosphere [e.g., Lithgow-Bertelloni and Guynn, 2004; Conrad et al., 2007], which are responsible for surface deformation. However, for the purpose of illustration we show the individual contributions of plate- and density-driven flow models separately. While density-driven flow tractions do not depend on the absolute mantle viscosity, plate-driven flow tractions depend on both imposed plate motion rates and the absolute 


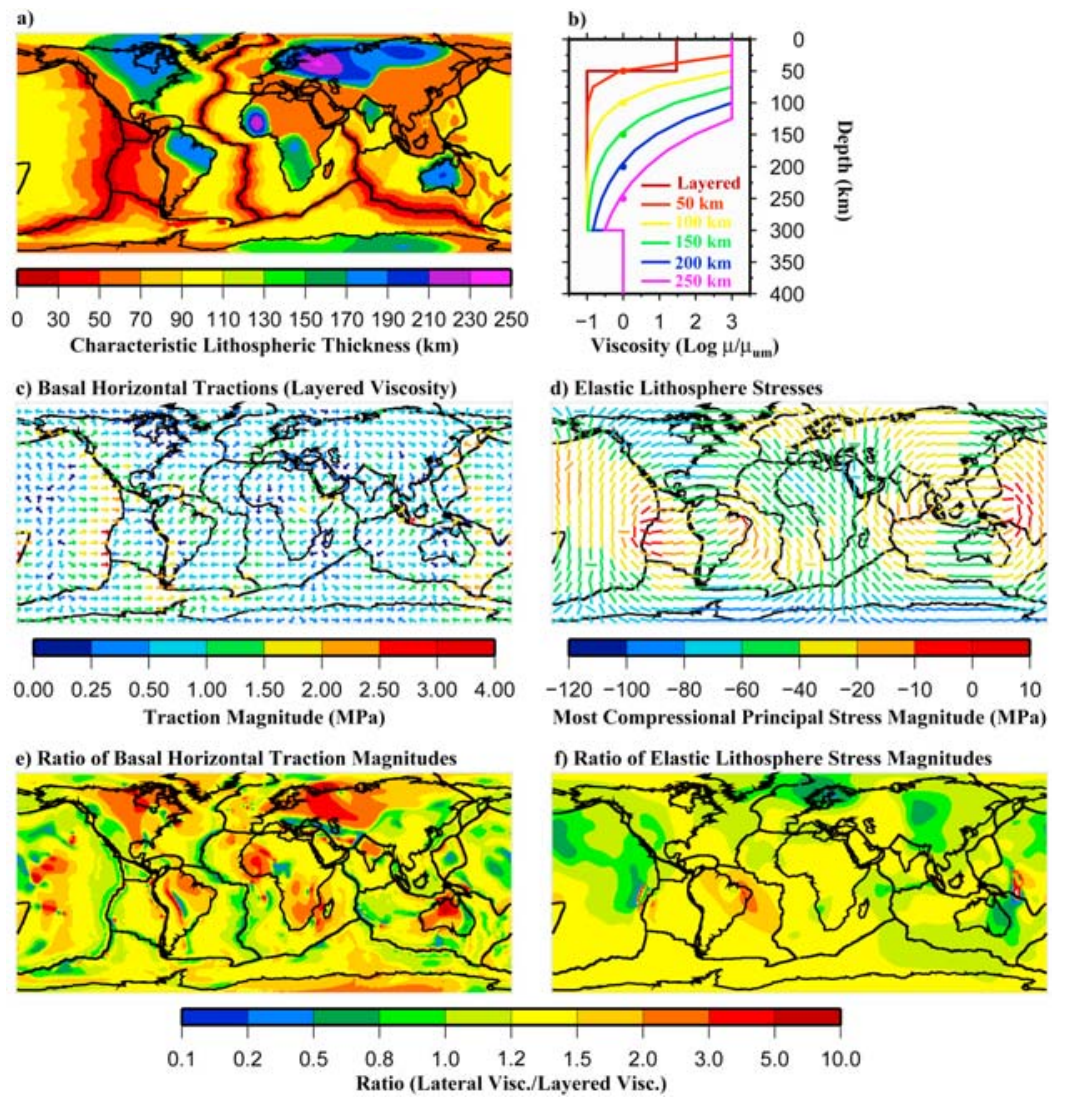

Figure 1. (a) Lithospheric thickness determined with a half-space cooling model for oceanic lithosphere and from the $1.5 \% \mathrm{~S}_{\mathrm{v}}$ contour (anomaly isosurface) from Gung et al. [2003] for continental lithosphere. (b) Depth versus $\log$ of the viscosity divided by the reference upper mantle viscosity $\left(\mu_{\mathrm{um}}\right)$ for layered and temperature-dependent viscosity structures. The maximum viscosity cutoff is set to $10^{3 *} \mu_{\mathrm{um}}$ and the dots in Figure $1 \mathrm{~b}$ indicate the depth at which basal tractions were measured for lithosphere of a given viscosity profile. (c) Orientation and magnitude of horizontal tractions measured at the base of the lithosphere for a layered viscosity structure and (d) the resulting most compressive elastic principal stress directions and magnitudes. The horizontal basal tractions are extracted from combined density- and plate-driven*0.5 flow fields. In the elastic models, compressive stresses are defined as negative. (e) Ratio of the magnitude of horizontal basal tractions and (f) related elastic most compressive principal stress between layered and laterally-varying (temperaturedependent) viscosity structures. The laterally-varying viscosity model contains minimum and maximum continental lithospheric thickness values of $50 \mathrm{~km}$ and $250 \mathrm{~km}$, respectively.

mantle viscosity [Conrad et al., 2007]. As a result, scaling the magnitude of plate-driven tractions in effect adjusts the assumed absolute mantle viscosity (i.e., the choice of $\int_{u m}$ in Fig. 1b). Due to the uncertainty associated with the absolute upper mantle viscosity, we examine cases where platedriven tractions assume an absolute upper mantle viscosity of $10^{21} \mathrm{~Pa} \mathrm{~s}$, or a value half as large (i.e., scaled by 0.5 ), which Conrad et al. [2007] found provided the best fit to anisotropy observations.

[5] Following our previous work we compare, for each flow model, a layered (radially symmetric) and a series of laterally-varying lithospheric viscosity structures (Figure 1b). For the layered case, the lithosphere, asthenosphere and lower mantle are 30, 0.1 and 50 times as viscous as the upper mantle, respectively. The lithospheric thickness is set to $50 \mathrm{~km}$ or $100 \mathrm{~km}$, and the asthenosphere extends from the lithospheric base to $300 \mathrm{~km}$. In models driven by surface plate motions, asthenospheric viscosities are assigned to points within $300 \mathrm{~km}$ of plate boundaries in order to dampen artificially high stress magnitudes associated with a singularity arising from the piecewise velocity boundary condition. Models with laterally-varying viscosity structures assign an error function profile above $300 \mathrm{~km}$ using a length scale consistent with half-space cooling for oceanic regions (with a maximum thickness of $100 \mathrm{~km}$ corresponding to seafloor older than $\sim 80 \mathrm{Ma}$ ) and the maximum depth of the $1.5 \% \mathrm{~S}_{\mathrm{v}}$ anomaly isosurface from the Gung et al. [2003] velocity model for continental regions (Figure 1a). The resulting temperature profile is converted to a viscosity structure using a temperature-dependent Arrhenius model with an activation energy of $200 \mathrm{~kJ} \mathrm{~mol}^{-1}$. Assigning different maximum $\left(H_{\max }\right)$ and minimum $\left(H_{\min }\right)$ continental lithospheric thicknesses modifies the viscosity structure (Figure 1b) and consequently changes traction magnitudes at the base of the lithosphere. Horizontal and radial tractions are extracted at the base of the lithosphere, defined by the viscosity contour $\mu=\mu_{u m}$, as indicated by the point along each curve in Figure 1b.

\subsection{Elastic Deformation}

[6] The elastic lithosphere's response to radial and horizontal basal tractions is computed using the finite element 

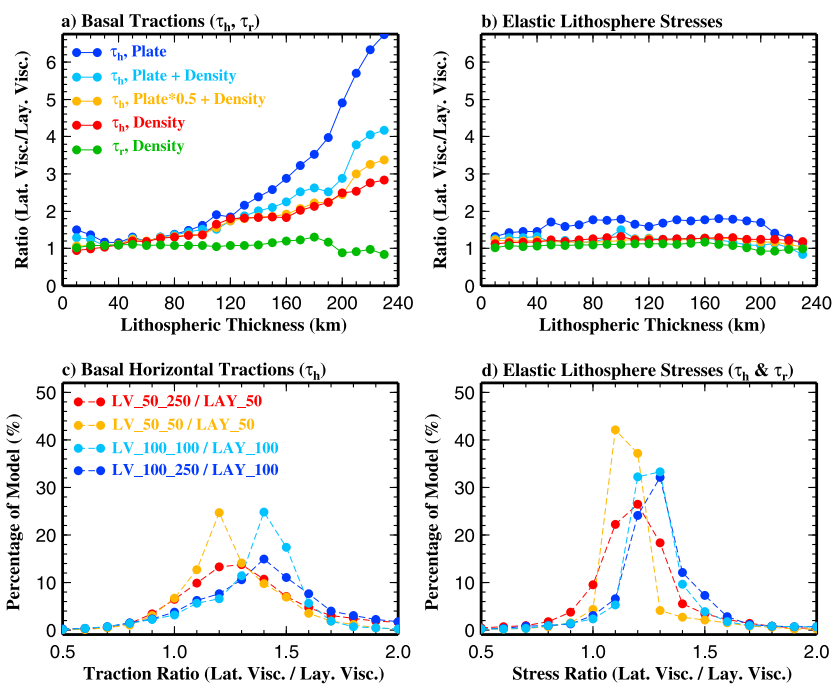

Figure 2. (a) Ratio (laterally-varying/layered viscosity) of horizontal $\left(\tau_{h}\right)$ and radial $\left(\tau_{r}\right)$ basal tractions magnitudes and (b) the most compressive elastic principal stress magnitudes as a function of lithospheric thickness. Curves are shown for plate-driven flow, density-driven flow, and combinations of density- and plate-driven flow. The layered viscosity thickness is $50 \mathrm{~km}$, and the laterally-varying viscosity models contain minimum and maximum continental lithospheric thickness values of $50 \mathrm{~km}$ and $250 \mathrm{~km}$, respectively. Regions where the elastic stress magnitude is less than $3 \%$ of the maximum value are not included in order to eliminate the influence of high ratio values associated with low absolute stress magnitudes. Percentage of a model with a given ratio (laterally-varying/layered viscosity) for (c) net horizontal basal tractions (Density$+0.5^{*}$ Plate-Driven) and (d) associated elastic lithosphere stresses (including the stresses generated by radial basal tractions, although tests show that the inclusion of radial tractions does not affect the percentage distributions significantly). Legend symbols describe the continental lithospheric structure associated with each percentage-ratio curve: $L V \_H_{\min \_} H_{\max } \sim$ laterally-varying viscosity $(L V)$, minimum continental lithospheric thickness $\left(H_{\min }\right)$ (note that when $H_{\min }=H_{\max }$ the continental thickness is constant but the oceanic thickness is not), maximum continental lithospheric thickness $\left(H_{\max }\right) ; L A Y H \sim$ layered viscosity $(L A Y)$, and lithospheric thickness $(\bar{H})$.

code ABAQUS v6.6 [Hibbitt and Sorensen, 2005] for a 3D linearly elastic spherical shell [Lithgow-Bertelloni and Guynn, 2004]. The elastic shell is composed of two layers, each consisting of a single layer of 8 node continuum shell elements (for all models) with a horizontal resolution of $110 \mathrm{~km}$. The upper and lower layers are $50 \mathrm{~km}$ and $100 \mathrm{~km}$ thick, respectively. Stress magnitudes scale inversely with the elastic layer thickness at these flow wavelengths. The Young's moduli of the upper and lower layers are $10^{11} \mathrm{~Pa}$ and $10^{6} \mathrm{~Pa}$, respectively, while Poisson's ratio remains fixed at 0.3 for both layers. The bottom nodes of the basal layer are pinned to prevent translation of the model. The low Young's modulus of the basal layer prevents stresses associated with the pinned basal nodes from affecting stresses in the stiffer upper element layer, where stresses are analyzed based on the applied loads.

[7] We compute the response of the elastic lithosphere to the radial tractions by separately computing the membrane stresses associated with dynamic topographic deflection and the gravitational sliding effect (gravitational potential energy) from the uplift and subsidence caused by the topography [Lithgow-Bertelloni and Guynn, 2004]. Dynamic deflections are given by $\tau_{r} /(\Delta \rho g)$, where $\tau_{r}$ is the radial stress at the base of the lithospheric mantle, $\Delta \rho$ is the density contrast between the lithosphere $\left(3200 \mathrm{~kg} \mathrm{~m}^{-3}\right)$ and surface (air $\sim 0 \mathrm{~kg} \mathrm{~m}^{-3}$, water $1020 \mathrm{~kg} \mathrm{~m}^{-3}$ ) and $g$ is the gravitational acceleration. Combining the elastic stresses related to basal shear, dynamic topography deflections and gravitational sliding give the total elastic stress response to the basal tractions.

\section{Results}

\subsection{Laterally-Varying Versus Layered Viscosity}

[8] Horizontal tractions on base of the lithosphere (density- $+0.5 *$ plate-driven) for a layered viscosity structure (50 km thick lithosphere) and the resulting elastic stresses exhibit long-wavelength patterns (Figures 1c and 1d) similar to those shown in previous work. Elastic stress magnitudes reflect integration of the basal horizontal tractions transmitted over plate-scale wavelengths and as a result are on average $\sim 1-2$ orders of magnitude higher than basal traction magnitudes. This is not surprising, as an examination of Love's thin shell equations reveals that the magnitude of stress resultants should be higher than applied tractions by a factor proportional to the ratio of the shell thickness to the radius of the sphere. Replacing the layered viscosity structure with a laterally-varying viscosity $\left(H_{\max }=\right.$ $250 \mathrm{~km}, H_{\min }=50 \mathrm{~km}$ ) magnifies the tractions in regions with deeply penetrating continental roots by up to a factor of 5 (Figure 1e) compared to the layered case. This is because the mantle tractions are transmitted more effectively to the overlying lithosphere if the asthenosphere is thin [Cooper and Conrad, 2009]. Variations greater than a factor of 5 only occur in regions with near zero traction magnitudes for the layered case. In contrast, changes in elastic stress magnitudes show little correlation with increases in the horizontal traction magnitude beneath thick continental lithosphere, and on average only change by a factor between 0.8 and 1.5 (Figure 1f). Although not shown, only minor variations in the orientation of the most compressive principal stress direction occur, as changes in the lithospheric viscosity structure strongly affect the magnitude but not direction of basal shear [Conrad and Lithgow-Bertelloni, 2006]. The stress regimes, which are largely controlled by radial traction patterns [e.g., Lithgow-Bertelloni and Guynn, 2004], also show insignificant variations because radial tractions are largely insensitive to viscosity structure (Figure 2a).

\subsection{Plate-Driven Versus Density-Driven Flow}

[9] Global averages of the ratio of basal tractions (Figure 2a) with and without laterally-varying viscosity for given lithospheric thicknesses $\left(H_{\max }=250 \mathrm{~km}, H_{\min }=50 \mathrm{~km}\right)$ show how increases in basal tractions with increasing lithospheric thickness vary for different combinations of density- and plate-driven flow. Flow driven by only density variations 
shows the smallest increase of the average horizontal traction magnitude ratios with increasing lithospheric thickness. This is due to the decrease in flow speed as coupling increases beneath thickened lithosphere for density-driven flow, while models that impose plate motions lack such a feedback mechanism because the strain rate is specified. Traction magnitude ratios increase as the component of plate-driven flow increases relative to the density-driven flow component (red through dark blue lines, Figure $2 \mathrm{a}$ ). In contrast, average ratios of the elastic principal stress magnitude remain roughly constant between 1.0 and 1.25 (Figure 2b), with the exception of pure plate-driven flow. This difference between patterns of basal tractions and elastic principal stresses reflects the effective transmission of stresses across large distances within an elastic lithosphere. As a result, the stress magnitude ratio for the elastic lithosphere represents an average of the basal traction ratios across plate-scale distances. Ratios of radial tractions (density-driven flow only) and the resulting elastic stresses show essentially no variation between layered and laterally-varying viscosity models (green lines, Figures $2 \mathrm{a}-$ 2b) because normal stresses are effectively transmitted across rheological boundaries, while shear stresses are not.

\subsection{Continental Lithospheric Thickness}

[10] Varying the maximum and minimum thickness of the continental lithosphere illustrates relations between global peaks in basal traction ratios (Figure 2c) and the associated elastic stress magnitude ratios (Figures 2d). For example, as the minimum thickness of the continental lithosphere increases from $50 \mathrm{~km}$ to $100 \mathrm{~km}$ (orange and red versus light blue and dark blue curves, Figures $2 c-2 d$ ), peaks in the distribution of both the basal horizontal tractions (Figure 2c) and the corresponding elastic stresses (Figure 2d) shift from ratio values of $\sim 1.2$ for $50 \mathrm{~km}$ to $1.3-1.4$ for $100 \mathrm{~km}$. For tractions, we have shown above that this amplification is due to the deeper average penetration of the lithosphere for thicker lithosphere. Significantly, this amplification occurs even when the continental thickness is fixed (orange and light blue curves) and equal to the lithospheric thickness in the layered viscosity model. For these cases, the tractions are amplified for the smoothly-varying viscosity structures (light red and yellow curves, Figure 1b) because these profiles reach the asthenospheric viscosity at a greater depth than the layered case (dark red curve, Figure 1b). In other words, the laterally-varying viscosity model has a higher "effective" lithospheric thickness than the corresponding layered case, which amplifies the tractions that mantle flow exerts on it. This amplified average traction magnitude is reflected in the average elastic stress magnitude.

[11] A restricted distribution of possible continental lithosphere thicknesses causes the peaks of the traction magnitude ratios to become higher and more laterally-restricted (orange and light blue curves compared to the red and dark blue curves, Figure 2c), reflecting the lithosphere thickness distribution that governs the traction magnitudes. However, the amplification of peaks for the elastic lithosphere stress distribution (Figure 2d) is not as large as it is for tractions (Figure 2c). This is because elastic stress magnitudes reflect a homogenization of the basal tractions, which tends to narrow and amplify the magnitude of the peak in the distribution of lithospheric stress ratios. Indeed, for any given continental structure, the peak of the elastic stress curve (Figure 2d) is higher and narrower than the corresponding peak of the traction ratio curve (Figure 2c) due to the transmission and resulting homogenization of the elastic stresses over large distances. Thus, the magnitude distribution of elastic stresses primarily reflects the average tractions applied to the lithosphere, rather than the variability in these tractions.

\section{Discussion and Conclusions}

[12] This study shows that amplification of lithospheremantle coupling beneath deeply penetrating continental roots is not accompanied by an equivalent amplification of stresses within the elastic lithosphere above continental roots, and produces no significant changes in stress regimes or orientations. Instead, the transmission of elastic stresses across large distances in the elastic lithosphere spreads any stress amplification over a wider area. Changes in elastic stress magnitudes centered over thick cratonic roots reflect both amplification of basal shear tractions beneath the thick roots, as well as changes in basal tractions over much thinner lithosphere, which constitute a much larger percentage of the model. Comparisons with stress observations [Lithgow-Bertelloni and Guynn, 2004] are unlikely to change significantly if variable plate-mantle coupling beneath thick continental lithosphere is taken into account.

[13] We note that the asthenospheric layer in all our models is only a factor of 10 less viscous than the upper mantle, smaller than some current estimates [e.g., Mitrovica and Forte, 2004]. Reducing the viscosity of the asthenosphere more than one order of magnitude would reduce the amplitude of plate-mantle coupling at deep continental roots slightly [Conrad and Lithgow-Bertelloni, 2006], yielding a small decrease in lithospheric stresses and deformation, when averaged globally. Larger lithosphere-asthenosphere viscosity contrasts are thus not likely to affect the observed relationship between changes in basal tractions and elastic stresses in any particular location. Large $\left(>10^{2}\right)$ viscosity contrasts between the lithosphere and asthenosphere, however, may play an important role in plate boundary regions where Ghosh et al. [2008] found that lithosphereasthenosphere viscosity contrasts of three orders of magnitude or greater provided the best fit to observed strain rate data.

[14] The minor changes in elastic stresses induced by more significant enhancements of mantle-lithosphere coupling at deep continental roots could change significantly if lateral variations in lithospheric strength prevented transmission of stresses across tectonic provinces. Previous work has shown that cratonic lithosphere can be effectively shielded from mantle-related stresses if it is bordered by weaker tectonic provinces that decouple the cratonic lithosphere from external stresses [Lenardic et al., 2000, 2003]. If in fact lateral changes in mechanical strength prevented transmission of stresses across some tectonic provinces, the lithosphere above thick continental roots would be much more sensitive to changes in mantle-lithosphere coupling because the elastic stress field would reflect only the stresses at the base of the thick roots. Modeling of the Australian continent [Dyksterhuis et al., 2005] and plate boundary regions [Ghosh et al., 2008] demonstrated that 
lateral changes in lithospheric strength can indeed have a large effect on stress patterns in vertically homogenous models. Thus, future studies should incorporate these variations where possible in order to accurately determine the length-scales over which basal stresses are transmitted. Similarly, vertical changes in the strength of the lithosphere [e.g., Kohlstedt et al., 1995] may play a strong role in decoupling basal shear from the upper parts of the lithosphere, as horizontal shear is transmitted much less effectively than radial stresses across rheological boundaries. Lithospheric models containing lateral and vertical variations in rheology and thickness are likely required to properly asses the relationship between mantle flow and lithospheric stress patterns. In that event, observations of stress and deformation patterns may provide new constraints on mantle viscosity structure and strength variations between lithospheric provinces, which are otherwise difficult to constrain [e.g., Paulson et al., 2007].

[15] Acknowledgments. We thank two anonymous reviewers for comments that improved the manuscript and Larry Ruff for many fruitful discussions and comments. All figures were prepared using GMT version 4.2.0 by P. Wessel and W. F. Smith. This work was supported by NSF grants EAR-0914712 (C.P.C.) and EAR-0609553 (C.L.-B.).

\section{References}

Bai, W., C. Vigny, Y. Ricard, and C. Froidevaux (1992), On the origin of deviatoric stresses in the lithospheres, J. Geophys. Res., 97, 11,72911,737, doi:10.1029/91JB00292.

Becker, T. W. (2006), On the effect of temperature and strain-rate dependent viscosity on global mantle flow, net rotation, and plate-driving forces, Geophys. J. Int., 167, 943-957, doi:10.1111/j.1365-246X.2006.03172.x.

Bird, P. (1998), Testing hypotheses on plate-driving mechanisms with global lithosphere models including topography, thermal structure, and faults, J. Geophys. Res., 103, 10115-10129, doi:10.1029/98JB00198.

Conrad, C. P., and C. Lithgow-Bertelloni (2006), Influence of continental roots and asthenosphere on plate-mantle coupling, Geophys. Res. Lett., 33, L05312, doi:10.1029/2005GL025621.

Conrad, C. P., M. Behn, and P. Silver (2007), Global mantle flow and the development of seismic anisotropy: Differences between the oceanic and continental upper mantle, J. Geophys. Res., 112, B07317, doi:10.1029/ 2006JB004608.

Cooper, C. M., and C. P. Conrad (2009), Does the mantle control the maximum thickness of cratons?, Lithosphere, 1, 67-72, doi:10.1130/ L40.1.

DeMets, C., R. Ordon, D. Argus, and S. Stein (1994), Effect of recent revisions to the geomagnetic reversal time scale on estimates of current plate motions, Geophys. Res. Lett., 21, 2191-2194, doi:10.1029/ 94GL02118.

Dyksterhuis, S., R. Muller, and R. Albert (2005), Paleostress field evolution of the Australian continent since the Eocene, J. Geophys. Res., 110, B05102, doi:10.1029/2003JB002728.
Ghosh, A., W. E. Holt, L. Wen, A. J. Haines, and L. M. Flesch (2008), Joint modeling of lithosphere and mantle dynamics elucidating lithospheremantle coupling, Geophys. Res. Lett., 35, L16309, doi:10.1029/ 2008GL034365.

Gung, Y. C., M. Panning, and B. Romanowicz (2003), Global anisotropy and the thickness of continents, Nature, 422, 707-711, doi:10.1038/ nature 01559 .

Hibbitt, K., and I. Sorensen (2005), ABAQUS Analysis Manual, Version 6.6, ABAQUS Inc., Pawtucket, R.I.

Karato, S.-I., and B. B. Karki (2001), Origin of lateral variation of seismic wave velocities and density in the deep mantle, J. Geophys. Res., 106, 21771-21783, doi:10.1029/2001JB000214.

Kohlstedt, D. L., B. Evans, and S. J. Mackwell (1995), Strength of the lithosphere: Constraints imposed by laboratory experiments, J. Geophys. Res., 100, 17,587-17,602, doi:10.1029/95JB01460.

Lenardic, A., L.-N. Moresi, and H. Muhlhaus (2000), The role of mobile belts for the longevity of deep cratonic lithosphere: The crumple zone model, Geophys. Res. Lett., 27, 1235-1238, doi:10.1029/1999GL008410.

Lenardic, A., L.-N. Moresi, and H. Muhlhaus (2003), Longevity and stability of cratonic lithosphere: Insights from numerical simulations of coupled mantle convection and continental tectonics, J. Geophys. Res., 108(B6), 2303, doi:10.1029/2002JB001859.

Lithgow-Bertelloni, C., and J. H. Guynn (2004), Origin of the lithospheric stress field, J. Geophys. Res., 109, B01408, doi:10.1029/2003JB002467.

Mitrovica, J. X., and A. M. Forte (2004), A new inference of mantle viscosity based upon joint inversion of convection and glacial isostatic adjustment data, Earth Planet. Sci. Lett., 225, 177-189, doi:10.1016/ j.eps1.2004.06.005.

Paulson, A., S. Zhong, and J. Wahr (2007), Inference of mantle viscosity from GRACE and relative sea level data, Geophys. J. Int., 171, 497-508, doi:10.1111/j.1365-246X.2007.03556.x.

Ritsema, J., H. van Heijst, and J. Woodhouse (2004), Global transition zone tomography, J. Geophys. Res., 109, B02302, doi:10.1029/ 2003JB002610.

Steinberger, B., H. Schmeling, and G. Marquart (2001), Large-scale lithospheric stress field and topography induced by global mantle circulation, Earth Planet. Sci. Lett., 186, 75-91, doi:10.1016/S0012-821X(01) 00229-1.

Tan, E., E. Choi, P. Thoutireddy, M. Gurnis, and M. Aivazis (2006), Geoframework: Coupling multiple models of mantle convection within a computational framework, Geochem. Geophys. Geosyst., 7, Q06001, doi:10.1029/2005GC001155.

Zhong, S. (2001), Role of ocean-continent contrast and continental keels on plate motion, net rotation of lithosphere, and the geoid, J. Geophys. Res., 106, 703-712, doi:10.1029/2000JB900364.

Zhong, S., M. Zuber, L. Moresi, and M. Gurnis (2000), Role of temperaturedependent viscosity and surface plates in spherical shell models of mantle convection, J. Geophys. Res., 105, 11,063-11,082, doi:10.1029/ 2000JB900003.

C. P. Conrad, Department of Geology and Geophysics, SOEST, University of Hawai'i at Mānoa, Honolulu, HI 96822, USA.

C. Lithgow-Bertelloni, Department of Earth Sciences, University College London, London WC1E 6BT, UK.

J. B. Naliboff, Department of Geological Sciences, University of Michigan, Ann Arbor, MI 48109, USA. (johnbn@umich.edu) 